\title{
Population and Disease-Based Prevalence of the Common Mutations Associated With Surfactant Deficiency
}

\author{
TAMI H. GARMANY, JENNIFER A. WAMBACH, HILLARY B. HEINS, JULIE M. WATKINS-TORRY, DANIEL J. WEGNER, \\ KATE BENNET, PING AN, GARLAND LAND, OLA D. SAUGSTAD, HOWARD HENDERSON, LAWRENCE M. NOGEE, \\ F. SESSIONS COLE, AND AARON HAMVAS
}

Departments of Pediatrics [T.H.G., J.A.W., H.B.H., J.M.W.-T., D.J.W., K.B., F.S.C., A.H.] and Genetics [P.A.], Washington University School of Medicine, St. Louis, Missouri 63110; Missouri Department of Health and Senior Services [G.L.], Jefferson City, Missouri 65102; Department of Pediatric Research [O.D.S.], University of Oslo, Oslo 0027 Norway; Department of Chemical Pathology [H.H.], University of Cape Town and NHLS, Cape Town, 7925 South Africa; Department of Pediatrics [L.M.N.], Johns Hopkins University, Baltimore, Maryland 21287

\begin{abstract}
The prevalence of the common mutations in the surfactant protein-B (121ins2), surfactant protein-C (I73T), and ATP-binding cassette member A3 (E292V) genes in populationbased or case-control cohorts of newborn respiratory distress syndrome (RDS) is unknown. We determined the frequencies of these mutations in ethnically diverse population and disease-based cohorts using restriction enzyme analysis (121ins2 and E292V) and a 5' nuclease assay (I73T) in DNA samples from population-based cohorts in Missouri, Norway, South Korea, and South Africa, and from a case-control cohort of newborns with and without RDS $(n=420)$. We resequenced the ATP-binding cassette member A3 gene $(A B C A 3)$ in E292V carriers and computationally inferred $A B C A 3$ haplotypes. The population-based frequencies of 121ins2, E292V, and $\mathrm{I73T}$ were rare $(<0.4 \%)$. E292V was present in $3.8 \%$ of newborns with RDS, a 10-fold greater prevalence than in the Missouri cohort $(p<0.001)$. We did not identify other loss of function mutations in $A B C A 3$ among patients with $\mathrm{E} 292 \mathrm{~V}$ that would account for their RDS. E292V occurred on a unique haplotype that was derived from a recombination of two common $A B C A 3$ haplotypes. E292V was over-represented in newborns with RDS suggesting that E292V or its unique haplotype impart increased genetic risk for RDS. (Pediatr Res 63: 645-649, 2008)
\end{abstract}

$\mathrm{T}_{\mathrm{s}}$ The pulmonary surfactant is a phospholipid-protein complex synthesized in alveolar type II cells and necessary for maintaining alveolar expansion at end-expiration. The pulmonary surfactant metabolic cycle includes synthesis, trafficking, processing, secretion, and recycling and maintains alveolar homeostasis (1). In symptomatic newborn infants and older children, mutations in three genes of the surfactant synthetic

Received October 17, 2007; accepted January 16, 2008.

Correspondence: Aaron Hamvas, M.D., Division of Newborn Medicine, St. Louis Children's Hospital, One Children's Place, St. Louis, MO 63110; e-mail: hamvas@kids.wustl.edu

This work was supported in part by grants from the American Philosophical Society Daland Fellowship [THG], the National Heart, Lung and Blood Institute (HL 65174 and HL 82747 [FSC], HL 65385 [AH], HL 54703 [LMN]), the Eudowood Foundation [LMN], and the Children's Discovery Institute and the Saigh Foundation [FSC and AH].

Preliminary results of this study were presented at the Pediatric Academic Societies' Meetings in Washington DC, May 2005 (PAS 2005:57:2509 and PAS 2005:57:2008), San Francisco, April 2006 (E-PAS2006:59:2610.1), and Toronto, May 2007 (EPAS2007:617935.18).

G.L. is currently at the National Association for Public Health Statistics and Information Systems, Silver Spring, MD.

Supplemental material available online at www.pedresearch.org. pathway, surfactant proteins-B and -C (SFTPB and SFTPC) and the ATP-Binding Cassette member A3 (ABCA3), disrupt surfactant function and cause respiratory disease in newborns and older children. Surfactant proteins-B (SP-B) and -C (SP-C) are hydrophobic peptides within the surfactant phospholipid layer that contribute to surface activity (2), whereas the ATP-binding cassette protein A3 (ABCA3) likely transports lipids, such as phosphatidylcholine, cholesterol, sphingomyelin, and phosphatidylglycerol, into lamellar bodies where the surfactant complex is assembled, processed, and stored (3-6).

SP-B is a 79-amino acid, hydrophobic protein encoded by a $9.7 \mathrm{~kb}$ gene, $S F T P B$. Infants homozygous for recessive lossof-function mutations in $S F T P B$ develop respiratory failure shortly after birth that is fatal without lung transplantation (7). The SFTPB allele most commonly observed in infants with SP-B deficiency ( $>60 \%$ of mutated alleles) results from a frameshift at codon 121 (121ins2) and is rare: less than 1 per 1000 individuals in two different population-based cohorts in the United States (8-10).

SP-C is a 35 amino acid hydrophobic protein, encoded by a $3 \mathrm{~kb}$ gene, SFTPC. Known mutations in SFTPC are expressed in a dominant fashion and have been associated with respiratory distress and interstitial lung disease in newborns and older children $(11,12)$. The most common SFTPC mutation is a single nucleotide transition that results in a threonine for isoleucine substitution at codon 73 (I73T) and is present in over $25 \%$ of the cases of SP-C associated disease (13).

ABCA3 is a 1704 amino acid protein, encoded by an $80 \mathrm{~kb}$ gene, $A B C A 3$. Several autosomal recessive mutations in $A B C A 3$ have been linked to lethal surfactant deficiency in newborns $(14,15)$ and to chronic respiratory insufficiency in older children (16). A missense mutation which introduces a valine for glutamic acid substitution at codon $292(\mathrm{E} 292 \mathrm{~V})$, when associated with another mutation on the other $A B C A 3$ allele, has been described in older, unrelated children with chronic lung disease (16).

\footnotetext{
Abbreviations: ABCA3, ATP-binding cassette, A3; SNPs, single nucleotide polymorphisms; SP-B, surfactant protein-B; SP-C, surfactant protein-C
} 
Previously, we reported a prevalence of approximately $0.8 / 1000$ for 121 ins 2 in an unselected cohort of anonymized bloodspots obtained from the Missouri Department of Health Newborn Screening Program (17). The frequencies of I73T and $\mathrm{E} 292 \mathrm{~V}$ in this population, and the frequencies of the three common surfactant pathway mutations in other geographically and ethnically diverse populations are unknown, as are their contributions to respiratory distress syndrome (RDS) in unselected populations of symptomatic newborns. To assess the population-attributable and disease-associated frequencies of these mutations that are rare in the general population but the most common of the disease-causing mutations in the three surfactant pathway genes, $S F T P B, S F T P C$, and $A B C A 3$, we used high throughput molecular screening methods in four ethnically and geographically diverse population-based cohorts and a single institution referral-based case-control cohort.

\section{METHODS}

Population-based cohorts. Anonymized DNA specimens were obtained from the Newborn Metabolic Screening Programs of Missouri, Norway, South Korea, and South African blacks (supplemental material, online). Ethnic and gender data were only available for the Missouri cohort, which was $51 \%$ male, $49 \%$ female, and comprised of $77 \%$ white, $20 \%$ black, and $3 \%$ individuals from other racial groups.

Case-control cohort. We obtained DNA and clinical data from healthy term newborns as a control group (CON) and from newborns with RDS referred to the Division of Newborn Medicine at St. Louis Children's Hospital for clinical care or genetic screening (Table 1). We defined RDS as the need for supplemental oxygen, a chest radiograph consistent with RDS and the need for continuous positive airway pressure or mechanical ventilation within the first $24 \mathrm{~h}$ of life. Because each of 16 twin-pairs had concordant results, only one twin from each pair was included in the analyses.

The Human Research Protection Office at the Washington University Medical Center and the Institutional Review Board at the Missouri Department of Health and Senior Services and of the respective countries' newborn screening programs approved this study. Informed consent was obtained from the parents of the infants in the case-control cohort.

Surfactant protein-B. We used SfuI restriction enzyme analysis to screen for 121 ins 2 after amplifying a 354 base pair fragment of exon 4 as described previously $(10,17)$ (supplemental material, online).

Surfactant protein- $\boldsymbol{C}$. We used a $5^{\prime}$ nuclease assay $\left(\operatorname{Taqman}^{\circledR}\right.$, Applied Biosystems) and the ABI 7500 FAST Real Time PCR System to genotype the I73T mutation. The assay produced a $61 \mathrm{bp}$ amplicon of exon 3, which included the thymine to cytosine transition responsible for I73T. Genomic DNA from individuals known to be heterozygous for I73T served as controls on each plate.

ATP-Binding Cassette member A3. We used BsrG1 restriction enzyme analysis to screen for $\mathrm{E} 292 \mathrm{~V}$ after amplifying a 682 base pair nucleotide fragment of exon 8 that contained the adenine to thymine transversion (16)(supplemental material, online). To determine whether those newborns with E292V and RDS carried other unique, functionally disruptive mutations in $A B C A 3$, we then amplified and sequenced $2 \mathrm{~kb}$ of the promoter region, the 30 coding and 2 noncoding exons, and splice site junctions of $A B C A 3$ for all

Table 1. Characteristics of case-control cohort

\begin{tabular}{lrc}
\hline & CON & RDS \\
\hline Race & & \\
Black & 102 & 70 \\
White & 77 & 142 \\
Other/missing & 2 & 27 \\
Sex & & \\
Male & 90 & 134 \\
Female & 91 & 102 \\
Missing & 0 & 3 \\
Birth weight (kg) & & $2.0 \pm 1.1$ \\
Mean \pm SD & $3.1 \pm 0.5$ & $33 \pm 5$ \\
EGA (wks) & $39 \pm 2$ & \\
Mean \pm SD & &
\end{tabular}

11 infants heterozygous for E292V and for 12 race and gestational age matched CON infants from the case-control cohort. Ethidium bromide agarose gel electrophoresis was performed on all amplicons to determine success of the amplification reaction and to identify differences in electrophoretic mobility that might suggest a gene insertion or deletion of more than 100 nucleotides. The amplification and sequencing strategies are described in Table S1 (supplemental material, online). A total of 74 single nucleotide polymorphisms (SNPs) were identified in these 23 individuals, 29 of which had a minor allele frequency $\geq 5 \%$ (Table $\mathrm{S} 2$, supplemental material, online). To determine whether the E292V mutation occurred on a common haplotype background, we computationally inferred $A B C A 3$ haplotypes using a Bayesian approach implemented in the PHASE computer software, and the 29 detected variants with minor allele frequency $\geq 5 \%$ (18).

We confirmed all mutations detected by restriction enzyme digestion or $5^{\prime}$ nuclease assay with direct sequencing as described in the supplemental material, online.

Data analysis. We used Phred, Phrap, PolyPhred, and Consed (http:// www.phrap.org/phredphrapconsed.html) to identify and annotate SNPs in sequencing chromatograms and Prettybase (http://pga.mbt.washington.edu) to extract a final file with genotypes. We used SAS (Version 9.1.3, SAS Institute, Cary, NC) to perform $\chi^{2}$ tests to determine distribution differences of categorical clinical characteristics and to perform Fisher's exact probability test to assess mutation frequency differences between groups. The Kruskal-Wallis test was used to compare ranked clinical characteristics where data normality and homoscedasticity were not assumed or Fischer's exact tests to determine differences in mutation frequency and categorical clinical characteristics and Kruskal-Wallis tests to compare numerical clinical characteristics (19). The SAS POWER procedure was also used to estimate statistical detection power separately in blacks (102 controls, 70 cases) and whites (77 controls, 142 cases) among our case-control cohort. In blacks, power was 36\% when 5\% dominant risk allele frequency difference or $13 \%$ recessive risk allele frequency difference was assumed, and power reached $88 \%$ when $11 \%$ dominant or $23 \%$ recessive risk allele frequencies were assumed. With the same assumptions, power estimates in whites were $43 \%$ and $93 \%$, respectively.

To determine whether variants located near exons in $A B C A 3$ had the potential to affect RNA splicing, we used a splice site prediction application available through the Berkeley Drosophila Genome Project (http:// www.fruitfly.org/seq_tools/splice.html).

\section{RESULTS}

Population-based cohorts. The 121ins2 mutation was not identified in the South African or Korean cohorts, but was similar in frequency in the Norwegian and Missouri cohorts (Table 2). Because we did not find I73T in over 4000 samples from the Missouri cohort, we decided not to screen other population-based cohorts for this mutation. We found E292V in $0.3-0.4 \%$ of the predominantly European descent cohorts (Norway and Missouri) but in $<0.1 \%$ of the Asian or African descent cohorts (Table 2).

Case-control cohort. No infants in the RDS or CON groups carried the I73T mutation, and one infant in the RDS group carried the 121ins2 mutation (Table 3). In contrast, the prevalence of E292V in the RDS cohort was 10-fold higher than that in the Missouri cohort $(3.8 \%, p<0.001)$; the prevalence of $\mathrm{E} 292 \mathrm{~V}$ in the CON cohort was not different from that of the Missouri cohort $(1.1 \%, p=0.2)$. One set of twins in each of the CON and RDS groups was positive for E292V. No patient heterozygous for E292V in the RDS group carried SNPs that would be predicted to disrupt splice site junctions or alter $\mathrm{ABCA} 3$ protein sequence (Table 4), nor were any large insertions or deletions detected. Furthermore, with the exception of one synonymous SNP (S1372S), all potentially functional SNPs were identified in one or more of the 12 comparison individuals. Individual RDS8, who died after 8 mo of mechanical ventilation, was the only one for whom lung histology was available. There was variable, but extensive interstitial fibrosis and pneumocyte hyperplasia, along with 
Table 2. Population-based frequencies

\begin{tabular}{lccccc}
\hline & Norway & South Africa-black & Korea & Missouri & Overall $p$ value across cohorts \\
\hline 121ins2 & $3 / 2501(0.1 \%)$ & $0 / 2044(0 \%)$ & $0 / 2596(0 \%)$ & $8 / 10,044(0.08 \%)^{*}$ & 0.2 \\
I73T & - & - & - & $0 / 4464(0 \%)$ & - \\
E292V & $8 / 2515(0.3 \%)$ & $0 / 1686(0 \%)$ & $0 / 1541(0 \%)$ & $4 / 1107(0.4 \%)$ & 0.004 \\
\hline
\end{tabular}

* Reported in Ref. 17.

Table 3. Disease-based frequencies

\begin{tabular}{lccc}
\hline & $\begin{array}{c}\text { CON } \\
(\mathrm{N}=181)\end{array}$ & $\begin{array}{c}\text { RDS } \\
(\mathrm{N}=239)\end{array}$ & $\begin{array}{c}p \text { value* } \\
\text { between groups }\end{array}$ \\
\hline 121ins2 & 0 & $1(0.4 \%)$ & 1.0 \\
I73T & 0 & 0 & - \\
E292V & $2(1 \%)$ & $9(3.8 \%)$ & 0.12 \\
\hline
\end{tabular}

* Fisher's exact probabilities.

alveolar macrophages, but without alveolar proteinosis. Normal appearing lamellar bodies and tubular myelin were seen by electron microscopy $(3,14,15,20)$.

Among the $15 A B C A 3$ haplotypes computationally inferred from the E292V and control cohorts $(n=23)$, we identified two common haplotypes among the 35 alleles that did not carry E292V: haplotype 1 with $13(37 \%)$ and haplotype 2 with $9(26 \%)$ (Table 5). Among the $11 \mathrm{E} 292 \mathrm{~V}$ carrying alleles, we identified one common haplotype $(n=8)$ and three unique haplotypes. The E292V haplotypes have two distinct blocks in common with each of the two most common nonE292V haplotypes: a 5-7 locus block from intron 1 to exon 9, seen in haplotype 2, and a 23-25 locus block from intron 8 through intron 28, seen in haplotype 1 . This combined haplotype background (CCAAACCCGG... ) was not seen in the absence of E292V, suggesting that E292V arose in conjunction with a recombination event between these two blocks and further suggests that the disease effect, if any, may not be solely because of E292V, but the unique combination of associated variants along the gene.

To assess whether E292V is associated with unique RDS characteristics, we compared demographic and clinical features in groups of RDS infants with and without E292V. Although the size of the cohort rendered limited statistical detection power, it appeared that the infants with E292V had a higher incidence of pneumothoraces (Table 6). The two most immature newborns with E292V (29 and 26 wk gestation) had evidence of more respiratory dysfunction (mechanical ventilation for $>1$ y and death because of chronic lung disease at 8 mo, respectively) than observed in newborn of similar gestational ages without E292V.

Table 4. Exonic and splice site SNPs identified in subjects with E292V

\begin{tabular}{|c|c|c|c|c|c|c|c|}
\hline Subject & Race/Sex & $\mathrm{SNP}(\mathrm{s}) *$ & Location & $\begin{array}{l}\text { Number of non-E292V } \\
\text { controls with variant }\end{array}$ & BW (kg) & GA (wks) & Outcome \\
\hline \multirow[t]{2}{*}{ CON1 } & $\mathrm{B} / \mathrm{M}$ & $\operatorname{Rs} 170447(\mathrm{~A}) \dagger$ & Ex $13+30$ & 1 & 3.6 & 41 & \\
\hline & & Rs323043 [P585P] (B) $\dagger$ & Ex 14 & 7 & & & \\
\hline CON2 & $\mathrm{W} / \mathrm{F}$ & $\mathrm{A}, \mathrm{B}$ & & & 2.6 & 37 & \\
\hline RDS1 & W/M & A, B & & & 3.6 & 38 & $\begin{array}{l}\text { PTX; vent } 4 \mathrm{~d}, \mathrm{O}_{2} 5 \mathrm{~d} \text {; } \\
\text { discharged RA }\end{array}$ \\
\hline RDS2A & $\mathrm{W} / \mathrm{F}$ & A, B & & & 2.3 & 35 & $\begin{array}{c}\text { Vent } 10 \mathrm{~d}, \mathrm{O}_{2} 5 \mathrm{~d} \\
\text { discharged RA }\end{array}$ \\
\hline RDS2B & $\mathrm{W} / \mathrm{F}$ & B & & & 2.1 & 35 & $\begin{array}{l}\text { PTX; vent } 14 \mathrm{~d}, \mathrm{O}_{2} 4 \mathrm{~d} \text {; } \\
\text { discharged RA }\end{array}$ \\
\hline \multirow[t]{5}{*}{ RDS3 } & $\mathrm{W} / \mathrm{M}$ & 16669 & Ex $5-11$ & 2 & & & Vent $1 \mathrm{y}, \mathrm{O} 21 \mathrm{y}$ \\
\hline & & A & & & & & \\
\hline & & Rs313908 & Ex $18-33$ & 0 & & & \\
\hline & & Rs313909 & Ex $18+34$ & 0 & & & \\
\hline & & Rs149532 [S1372] & Ex 26 & 0 & & & \\
\hline RDS4 & $\mathrm{W} / \mathrm{M}$ & $\mathrm{B}$ & & & 2.9 & 37 & $\begin{array}{l}\text { PTX; vent } 10 \mathrm{~d}, \mathrm{O}_{2} 6 \mathrm{~d} \text {; } \\
\text { discharged RA }\end{array}$ \\
\hline RDS5 & $\mathrm{W} / \mathrm{M}$ & 45305 & Ex $17-17$ & 1 & 3.8 & 36 & $\begin{array}{c}\text { Vent } 4 \mathrm{~d}, \mathrm{O}_{2} 1 \mathrm{~d} \\
\text { discharged RA }\end{array}$ \\
\hline RDS6 & $\mathrm{W} / \mathrm{F}$ & Rs149532 [S1372S] & Ex 26 & 0 & 2.5 & 33 & $\begin{array}{l}\text { Vent for } 12 \mathrm{~d}, \mathrm{O} 2 \text { for } 18 \mathrm{~d} \text {, } \\
\text { then RA; died at } 8 \text { wks, } \\
\text { non respiratory causes }\end{array}$ \\
\hline \multirow[t]{3}{*}{ RDS7 } & $\mathrm{W} / \mathrm{F}$ & $21289[\mathrm{~A} 227 \mathrm{~A}]$ & Ex 7 & 1 & 3.1 & 39 & CPAP for $2 \mathrm{~d}$ \\
\hline & & Rs13332547 & Ex $9-20$ & 3 & & & $\mathrm{O}_{2}$ for $4 \mathrm{~d}$; discharged $\mathrm{RA}$ \\
\hline & & Rs13332514 [F353F] & Ex 9 & 3 & & & \\
\hline RDS8 & W/M & None & & & 0.7 & 26 & $\begin{array}{l}\text { Died at } 8 \text { mo, entirely vent } \\
\text { dependent }\end{array}$ \\
\hline RDS9 & $\mathrm{W} / \mathrm{M}$ & None & & & 2.6 & 37 & $\begin{array}{l}\text { PTX, vent for } 13 \mathrm{~d}, \mathrm{O}_{2} \text { for } \\
\quad 6 \mathrm{mo}\end{array}$ \\
\hline
\end{tabular}

* rs numbers through dbSNP (http://www.ncbi.nlm.nih.gov/SNP); if no rs number available, then the number refers to the genomic location from the ABCA3 sequence generated by Seattle SNPs (http://pga.gs.washington.edu/data/abca3/abca3.ColorFasta.html).

$\dagger$ A, B: common variants found in multiple individuals.

PTX, pneumothorax; Vent, mechanical ventilation; RA. room air. 
Table 5. Computational haplotypes identified in 23 individuals

\begin{tabular}{|c|c|c|c|}
\hline Group & Haplotype \# & Haplotype & Alleles, $\mathrm{N}(\%)^{*}$ \\
\hline \multirow[t]{8}{*}{ nonE292V } & 1 & CCGACCCCGGCAATCCGAAACTACAGGGTA & $13(37)$ \\
\hline & 1a & CCGACCCCGGCADCTCCAAAGCACTGGGCC & $1(3)$ \\
\hline & $1 \mathrm{~b}$ & CCGACCCCGGCGDCTGCGGACCGCATAATC & $1(3)$ \\
\hline & $1 \mathrm{c}$ & CCGACCCCGGAGDTTCCGGACCGCATAATC & $2(6)$ \\
\hline & $1 \mathrm{~d}$ & CCGACCCTGGCAATCCGAAACTACAGGGTA & $1(3)$ \\
\hline & $1 \mathrm{e}$ & CCGACTTTGGAGDTTCCGGACCGCATAATC & $2(6)$ \\
\hline & 1f & TTGACCCCGGCAATCCGAAACTACAGGGTA & $1(3)$ \\
\hline & $1 \mathrm{~g}$ & TTGACTTTGGAGDTTCCGGACCGCATAATC & $2(6)$ \\
\hline \multirow[t]{3}{*}{ nonE292V } & 2 & CCAAACCTAACGDCTGGAAGGCATTGGGCC & $9(26)$ \\
\hline & $2 \mathrm{a}$ & CCAAACCTAACADCTGGAAGGCATTGGGCC & $2(6)$ \\
\hline & $2 \mathrm{~b}$ & CCAAACCTAACGDCTGGAAGCCATTGGGCC & $1(3)$ \\
\hline \multirow[t]{4}{*}{ E292V } & 3 & CCAT $†$ ACCCGGCAATCCGAAACTACAGGGTA & $8(73)$ \\
\hline & $3 \mathrm{a}$ & CCATACCCGGCAATCCGAAGCTACAGGGTA & $1(9)$ \\
\hline & $3 b$ & CCATACCCGGCAATTCGAAACTACAGGGTC & $1(9)$ \\
\hline & $3 c$ & CCATACCCGACAATCCGAAACTACAGGGTA & $1(9)$ \\
\hline
\end{tabular}

* Percent of alleles with or without E292V.

$\dagger \mathrm{E} 292 \mathrm{~V}$ is an A > T transversion; shaded CC is indeterminate as to which haplotype from which it was derived.

Table 6. Comparison of E292V positive newborns with RDS cohort (including twins)

\begin{tabular}{lccc}
\hline & E292V with RDS & RDS without E292V \\
& $\mathrm{N}=10$ & $\mathrm{~N}=237$ & $p$ value \\
\hline BW & $2.6(0.7-3.8)$ & $1.8(0.5-4.5)$ & $0.10^{*}$ \\
& & 201 & \\
EGA & $36(26-39)$ & $34(23-43)$ & $0.30^{*}$ \\
& & 218 & \\
Race (ED/AD) & $10 / 0$ & $139 / 72 / 26 \mathrm{w}$ & $0.04 \dagger$ \\
Sex (F/M) & $4 / 6$ & $101 / 133$ & $1.0 \dagger$ \\
Pneumothorax & $4(40 \%)$ & $29(15 \%)$ & $0.06^{\dagger}$ \\
Duration mech & $8(1-450)$ & $14(0-358)$ & $0.46^{*}$ \\
$\quad$ vent/CPAP & \multicolumn{4}{c}{171} & \\
Duration O2 & $18(3-800)$ & $26(0-358)$ & $0.90^{*}$ \\
& & 171 & \\
Outcome at discharge & & & \\
On O2 & $3(38 \%)$ & $75(43 \%)$ & $0.71^{*}$ \\
Vent & $1(10 \%)$ & $9(5 \%)$ & $0.24^{*}$ \\
Survive & $8(80 \%)$ & $147(86 \%)$ & $0.64^{*}$ \\
\hline
\end{tabular}

* Kruskal-Wallis test.

$\dagger$ Fisher's exact test.

\section{DISCUSSION}

The autosomal recessive 121ins2 (SFTPB) and autosomal dominant I73T (SFTPC) mutations most frequently detected in infants with lethal surfactant deficiency and interstitial lung disease are rare in the general population and in unselected infants with RDS, observations that suggest that these specific mutations have low population-attributable risk of RDS. $S F T P B$ haploinsufficient murine lineages that demonstrate decreased lung compliance and air trapping at birth suggest that infants heterozygous for 121 ins 2 may have increased risk or severity of RDS $(21,22)$. However, the observation that 121 ins 2 heterozygous siblings and parents of SP-B deficient infants are asymptomatic at birth coupled with the rarity of loss of function mutations in SFTPB suggests that these mutations would not be over-represented in a small cohort of premature and term infants with RDS $(23,24)$. Although infants with mutations in SFTPC can present as RDS in the newborn period, most children with these mutations become symptomatic with interstitial lung disease beyond the newborn period, especially those with I73T $(13,25)$. Therefore, it is also not surprising that we did not find $\mathrm{I} 73 \mathrm{~T}$ in the cohort of children who developed respiratory disease at birth.

We only screened for E292V in $A B C A 3$, and, whereas the E292V carrier frequency is 3- to 5-fold higher than 121ins2 or I73T carrier frequencies in population-based cohorts of primarily European descent (Norway and Missouri) and we cannot exclude the possibility that other mutations in ABCA3 are just as common, the 10-fold enrichment in E292V prevalence in our RDS cohort suggests that E292V may increase the risk and/or severity of RDS in susceptible newborns. The developmental, environmental, and/or genetic background factors that contribute to differences in penetrance of these mutations remain to be defined.

Although disease-causing variants other than 121ins2 and E292V in SFTPB and ABCA3 are highly prevalent in cohorts of infants selected for lethal respiratory distress, they have primarily been identified in single individuals or families $(3,14,26)$. We did not have sufficient power to pursue the contribution of these more rare mutations to the disease-based risk for RDS in our neonatal intensive care unit cohort that was not enriched for lethal RDS. Common variants in $S F T P B$ and $S F T P C$ with minor allele frequencies $\geq 0.2$ have also been associated with the risk for RDS, but the mechanisms by which these variants and combinations thereof impart risk are undetermined (27-30). To our knowledge, the contribution of common variants in $A B C A 3$ to the risk of RDS has not been evaluated. In view of the contributions of $S F T P B, S F T P C$, and $A B C A 3$ to surfactant function necessary for successful fetalneonatal pulmonary transition, the low population-attributable risk of genetically disruptive mutations is not surprising.

The mechanism by which E292V may disrupt surfactant synthesis is unknown. Codon 292 is part of an intracellular loop between two transmembrane domains of the ABCA3 protein and the substitution of a nonpolar hydrophobic amino acid for a negatively charged hydrophilic amino acid may disrupt phospholipid binding and transport into the lamellar body. In vitro studies suggest a primary role for $A B C A 3$ mutations in the disruption of pulmonary surfactant metabolism through abnormalities in intracellular protein trafficking, 
defects in ATP hydrolysis, or abnormal phospholipid packaging $(3-6,31,32)$. In addition, ABCA3 protein expression has been shown to increase with advancing gestation (33). These observations, along with other reports of lethal and chronic respiratory disease in the presence of a single mutation in $A B C A 3$, suggest that $\mathrm{E} 292 \mathrm{~V}$ itself, or through interactions with variants in other genes, could disrupt $\mathrm{ABCA} 3$ function in developmentally susceptible individuals $(14,16,26,34)$. In contrast to those reports, however, all but one infant in this study recovered from their lung disease.

The unique haplotype associated with E292V raises the possibility that a specific combination of variants within this new block could confer the phenotype. Our resequencing strategy that focused on coding regions and flanking sequence did not identify any coding or splice site variants either upstream or downstream of E292V that would obviously alter $\mathrm{ABCA} 3$ function, but it is possible that functional intronic or promoter variants reside within the regions that were not sequenced or in other genes along the surfactant synthetic pathway.

Taken together, these data suggest that E292V may increase RDS susceptibility in the context of currently unknown developmental, genetic, or environmental traits. Even though the 121ins2, I73T, and E292V mutations are rare in the general population, they are sufficiently prevalent to warrant evaluation in the context of respiratory compromise that seems disproportionate for gestational age.

Acknowledgments. The authors thank Dong-Hee Cho, M.D., Director of Clinical Pathology at Cheil General Hospital, Seoul, South Korea for providing bloodspots from South Korea, the Missouri Department of Health and Senior Services for providing bloodspots and linked vital statistics data, and Frances V. White, M.D., Department of Pathology, Washington University for providing analysis of lung histology and ultrastructure. The authors also thank Ping Yang, Kim Fitzroy, and Michelle Trusgnich for technical support.

\section{REFERENCES}

1. Batenburg JJ 1992 Surfactant phospholipids: synthesis and storage. Am J Physiol 262:L367-L385

2. Weaver TE, Conkright JJ 2001 Function of surfactant proteins B and C. Annu Rev Physiol 63:555-578

3. Garmany TH, Moxley MA, White FV, Dean M, Hull WM, Whitsett JA, Nogee LM, Hamvas A 2006 Surfactant composition and function in patients with ABCA3 mutations. Pediatr Res 59:801-805

4. Cheong N, Madesh M, Gonzales LW, Zaho M, Yu K, Ballard PL, Shuman H 2006 Functional and trafficking defects in ABCA3 mutants associated with respiratory distress syndrome. J Biol Chem 281:9791-9800

5. Ban N, Matsumura Y, Sakai H, Takanezawa Y, Sasaki M, Arai H, Inagaki N 2007 ABCA3 as a lipid transporter in pulmonary surfactant biogenesis. J Biol Chem 282:9628-9634

6. Fitzgerald ML, Haley KJ, Welti R, Goss JL, Brown CE, Zhuang DZ, Bell SA, Lu N, Mckee M, Seed B, Freeman MW 2007 ABCA3 inactivation in mice causes respiratory failure, loss of pulmonary surfactant, and depletion of lung phosphatidylglycerol. J Lipid Res 48:621-632

7. Hamvas A, Nogee LM, Mallory GB, Spray TL, Huddleston CB, August A, Dehner LP, deMello DE, Moxley M, Nelson R, Cole FS, Colten HR 1997 Lung transplantation for treatment of infants with surfactant protein B deficiency. J Pediatr 130:231-239
8. Nogee LM, Garnier G, Dietz HC, Singer L, Murphy AM, deMello DE, Colten HR 1994 A mutation in the surfactant protein B gene responsible for fatal neonatal respiratory disease in multiple kindreds. J Clin Invest 93:1860-1863

9. Hamvas A 1997 Inherited surfactant protein-B deficiency. Adv Pediatr 44:369-388

10. Cole FS, Hamvas A, Rubinstein P, King E, Trusgnich M, Nogee LM, deMello DE, Colten HR 2000 Population-based estimates of surfactant protein B deficiency. Pediatrics 105:538-541

11. Nogee LM, Dunbar AE III, Wert SE, Askin F, Hamvas A, Whitsett JA 2001 A mutation in the surfactant protein $\mathrm{C}$ gene associated with familial interstitial lung disease. N Engl J Med 344:573-579

12. Hamvas A, Nogee LM, White FV, Schuler P, Hackett BP, Huddleston CB, Mendeloff EN, Hsu FF, Wert SE, Gonzales LW, Beers MF, Ballard PL 2004 Progressive lung disease and surfactant dysfunction with a deletion of surfactant protein $\mathrm{C}$ gene. Am J Respir Cell Mol Biol 30:771-776

13. Cameron HS, Somaschini M, Carrera P, Hamvas A, Whitsett JA, Wert SE, Deutsch G, Nogee LM 2005 A common mutation in the surfactant protein C gene associated with lung disease. J Pediatr 146:370-375

14. Shulenin S, Nogee LM, Annilo T, Wert SE, Whitsett JA, Dean M 2004 ABCA3 gene mutations in newborns with fatal surfactant deficiency. N Engl J Med 350:12961303

15. Brasch F, Schimanski S, Muhlfeld C, Barlage S, Langmann T, Aslanidis C, Boettcher A, Dada A, Schroten H, Mildenberger E, Prueter E, Ballmann M, Ochs M, Johnen G, Griese M, Schmitz G 2006 Alteration of the pulmonary surfactant system in full-term infants with hereditary ABCA3 deficiency. Am J Respir Crit Care Med 174:571-580

16. Bullard JE, Wert SE, Whitsett JA, Dean M, Nogee LM 2005 ABCA3 mutations associated with pediatric interstitial lung disease. Am J Respir Crit Care Med 172:1026-1031

17. Hamvas A, Trusgnich M, Brice H, Baumgartner J, Hong Y, Nogee LM, Cole FS 2001 Population-based screening for rare mutations: high throughput DNA extraction and amplification from Guthrie cards. Pediatr Res 50:666-668

18. Stephens M, Smith NJ, Donnelly P 2001 A new statistical method for haplotype reconstruction from population data. Am J Hum Genet 68:978-989

19. Rosner B 1999 Fundamentals of Biostatistics. Duxbury Press, Pacific Grove, CA, pp 371-376

20. Tryka AF, Wert SE, Mazursky JE, Arrington RW, Nogee LM 2000 Absence of lamellar bodies with accumulation of dense bodies characterizes a novel form of congenital surfactant defect. Pediatr Dev Pathol 3:335-345

21. Clark JC, Iwamoto HS, Ikegami M, Jobe AH, Hull WM, Whitsett JA 1997 Decreased lung compliance and air trapping in heterozygous SP-B deficient mice. Am J Respir Cell Mol Biol 16:46-52

22. Tokieda K, Iwamoto HS, Bachurski C, Wert SE, Hull WM, Ikeda K, Whitsett JA 1999 Surfactant protein-B-deficient mice are susceptible to hyperoxic lung injury. Am J Respir Cell Mol Biol 21:463-472

23. Yusen RD, Cohen AH, Hamvas A 1999 Normal lung function in subjects heterozygous for surfactant protein B deficiency. Am J Respir Crit Care Med 159:411-414

24. Hamvas A, Wegner DJ, Carlson CS, Bergmann KR, Trusgnich MA, Fulton L, Kasai Y, An P, Mardis ER, Wilson RK, Cole FS 2007 Comprehensive genetic variant discovery in the surfactant protein B gene. Pediatr Res 62:170-175

25. Hamvas A 2006 Inherited surfactant protein-B deficiency and surfactant protein-C associated disease: clinical features and evaluation. Semin Perinatol 30:316-326

26. Somaschini M, Nogee LM, Sassi I, Danhaive O, Presi S, Boldrini R, Montrasio C, Ferrari M, Wert SE, Carrera P 2007 Unexplained neonatal respiratory distress due to congenital surfactant deficiency. J Pediatr 150:649-653

27. Floros J, Thomas NJ, Liu W, Papagaroufalis C, Xanthou M, Pereira S, Fan R, Guo X, Diangelo S, Pavlovic J 2006 Family-based association tests suggest linkage between surfactant protein B (SP-B) (and flanking region) and respiratory distress syndrome (RDS): SP-B haplotypes and alleles from SP-B-linked loci are risk factors for RDS. Pediatr Res 59:616-621

28. Haataja R, Ramet M, Marttila R, Hallman M 2000 Surfactant proteins A and B as interactive genetic determinants of neonatal respiratory distress syndrome. Hum Mol Genet 9:2751-2760

29. Hamvas A, Wegner DJ, Trusgnich MA, Madden KK, Heins H, Liu Y, Rice T, Watkins-Torry J, Cole FS 2005 Genetic variant characterization in intron 4 of the surfactant protein B gene. Hum Mutat 26:494-495

30. Lahti M, Marttila R, Hallman M 2004 Surfactant protein C variation in the Finnish population-association with perinatal respiratory disease. Eur J Hum Genet $12: 312-320$

31. Matsumura Y, Ban N, Ueda K, Inagaki N 2006 Characterization and classification of ATP-binding cassette transporter ABCA3 mutants in fatal surfactant deficiency. J Biol Chem 281:34503-34514

32. Mulugeta S, Gray JM, Notarfrancesco KL, Gonzales LW, Koval M, Feinstein SI, Ballard PL, Fisher AB, Shuman H 2002 Identification of LBM180, a lamellar body limiting membrane protein of alveolar type II cells, as the $\mathrm{ABC}$ transporter protein ABCA3. J Biol Chem 277:22147-22155

33. Stahlman MT, Besnard V, Wert SE, Weaver TE, Dingle S, Xu Y, von Zychlin K, Olson SJ, Whitsett JA 2007 Expression of ABCA3 in developing lung and other tissues. J Histochem Cytochem 55:71-83

34. Bullard JE, Nogee LM 2007 Heterozygosity for ABCA3 mutations modifies the severity of lung disease associated with a surfactant protein-C gene (SFTPC) mutation. Pediatr Res 62:176-179 